\title{
Evolução industrial: o caso da fusão de uma empresa do setor alimentício
}

\author{
Industrial evolution: the case of the merger of a company in the food sector
}

Recebido: 28/10/2021 | Revisado: 03/11/2021 | Aceito: 08/11/2021 | Publicado: 11/11/2021

\author{
Moisés Carlos Muniz Barros \\ ORCID: https://orcid.org/0000-0001-9806-2610 \\ Universidade Federal de Campina Grande, Brasil. \\ E-mail:moisescarlos10.13@gmail.com \\ Isabel Lausanne Fontgalland \\ ORCID: https://orcid.org/0000-0002-0087-2840 \\ Universidade Federal de Campina Grande, Brasil \\ E-mail: isabelfontgalland@gmail.com
}

\begin{abstract}
Resumo
A Sadia, grande empresa no ramo frigorífico do Brasil, tem sua criação no ano de 1944 em Concórdia no estado de Santa Catarina, empresa familiar e desde então seu desenvolvimento foi notório pela sua história no Brasil. Através de investimentos, modernização e higiene de suas atividades no ramo alimentício a empresa desenvolveu nacionalmente quando ocorreu assim a fusão com a Perdigão em 2008, outra grande empresa no mesmo setor, formando assim a Brasil Foods - BRF, expandindo-se para 140 países entre eles o Oriente Médio, Europa, Extremo Oriente, América Latina e África. O presente estudo de caso tem por objetivo apresentar a criação e o desenvolvimento da empresa como também a sua importância para o desenvolvimento da indústria alimentícia no nosso país.
\end{abstract}

Palavras Chave: Sadia; Frigorífico; Setor Alimentício.

\begin{abstract}
Sadia, a large company in the meat packing industry in Brazil, was created in 1944 in Concórdia, Santa Catarina, in a family manner and since then its development has been notorious for its history in Brazil. Through investments, modernization and hygiene of its activities in the food sector, the company developed nationally when it merged with Perdigão in 2008, another large company in the same sector, thus forming Brasil Foods - BRF, expanding to 140 countries across the Middle East, Europe, Far East, Latin America and Africa. This case study aims to present the creation and development of the company as well as its importance for the development of the food industry in our country.
\end{abstract}

Keywords: Sadia; Fridge; Food Sector.

\section{Introdução}

O tema abordado neste estudo refere-se à criação e desenvolvimento da empresa Sadia, no território nacional brasileiro, especificamente na região sul, até sua expansão de forma internacional. Desta, inclui-se, todos os processos pelos quais fizeram com que sua modernização nos equipamentos, suas práticas de higiene e investimentos em capital humano resultaram na sua expansão no setor frigorífico.

O estudo versa sobre a história empresarial contendo informações de consulta bibliográficas como também fontes da própria empresa que disponibiliza sua trajetória de como foram as décadas referentes a sua expansão.

Na primeira parte do estudo, está abordado o início da empresa iniciada pelo comerciante, Attilio Fontana, que em 1947, esteve à frente do conglomerado. Na segunda parte do estudo, será cunhada, a evolução da empresa no setor frigorífico e sua expansão, na diversidade de seus produtos, com abates bovinos, suínos e aves. Por fim, apresentar-se-á a alavancagem empresarial, com a fusão Sadia - Perdigão, apresentando as derivações desse passo empresarial. 


\section{Metodologia}

O método utilizado neste trabalho é o estudo de caso da empresa SADIA com base em Yin, 2015. De acordo com Bruney, Herman e Schoutheete (Duarte \& Barros, 2006), um estudo de caso define-se como uma análise, intensiva, empreendida numa única ou em algumas organizações reais, pois reúne, tanto quanto possível, informações numerosas e detalhadas para apreender a totalidade de uma situação, assim estabelece critérios para ser estudado.

No desenvolvimento da pesquisa, um estudo de caso enumera-se quatro características fundamentais: o Particularismo, a Descrição, a Explicação e a Indução, onde os estudos de caso não buscam a generalização de seus resultados, mas sim a compreensão e interpretação mais profunda dos fatos e fenômenos específicos. Desta forma, este presente estudo utilizou-se desta metodologia para desenvolvimento da pesquisa de acordo com Bruney, Herman e Schoutheete (Duarte \& Barros, 2006) e em Wimmer (1996, p. 161) consolidando o conteúdo da pesquisa.

A coleta de informações consolidadas, referente a empresa Sadia, foi feita no próprio site da empresa, onde contém sua história desde 1947, trilhando os primeiros passos comerciais do seu fundador. Outra parte dos dados informacionais da empresa foram coletados por estudos já realizados com revisão de pares consolidando sua veracidade.

\section{O Surgimento e Expansão da Sadia no Território Nacional}

Como qualquer outra empresa do setor de frigorífico, o começo foi modesto e o gerenciamento ficou a cargo da família. Dados os prósperos negócios da região sudeste, nos anos de 1944, Attilio Fontana, rico comerciante de Santa Catarina, comprou e reativou o Frigorifico Concórdia, passando a se chamar Indústria e Comercio Concórdia (Sadia, 2009). Com uso de capital próprio, registrou a marca SADIA em 1947. De início, com um pequeno abate de suínos e um quadro de 50 funcionários. Com a evolução dos negócios, após dois anos já se registrava um abate de 100 suínos/dia e se comercializava os resíduos do abate também (banha, salames, presunto, etc) configurando a primeira intenta de mix de produtos da região.

Nos anos 50, aparece a principal dificuldade logística: transportar de seus produtos pela região sul e sudeste. Em 1960 também S.A. Indústria e Comercio Concórdia, já entrará no comercio de abates de aves, com 90.000 aves abatidas, dominando $70 \%$ deste comercio, em âmbito nacional. Com esse desenvolvimento, também, a empresa incluiu o abate de perus, patos conquistando concomitante também uma linha de crédito junto ao BNDES. (Costa, 2009). Nos anos de 1980 e 1990 , houve a aquisição de outros frigoríficos menores, e a entrada da empresa nos ramos de margarina, massas e empanados. Já em meados dos anos 90, em diante, verificou-se que a empresa estava focalizada, agora em investir em produção de massas, margarinas, empanados e sobremesas, o que demonstra a preocupação da empresa em atender os mercados mais lucrativos.

A empresa, já apresentando um grande patrimônio empresarial em meados de 2005 tinha que se ter uma boa gestão de dados e assim aderiu ao sistema S.A.P, sistema gerencial produzido por uma softhouse alemã, o qual em suas matrizes são Concórdia (matriz fiscal) e São Paulo (matriz administrativa) interligadas e mantendo o controle toda a burocracia administrativa e produtiva de suas unidades. (Dalla, 2009)

A Figura 1 abaixo apresenta como era a comunicação, interligação das unidades da Sadia referenciando já nos anos de 2003 de acordo com a região sul: 
Figura 1 - Organograma: comércio de aves na região sul.

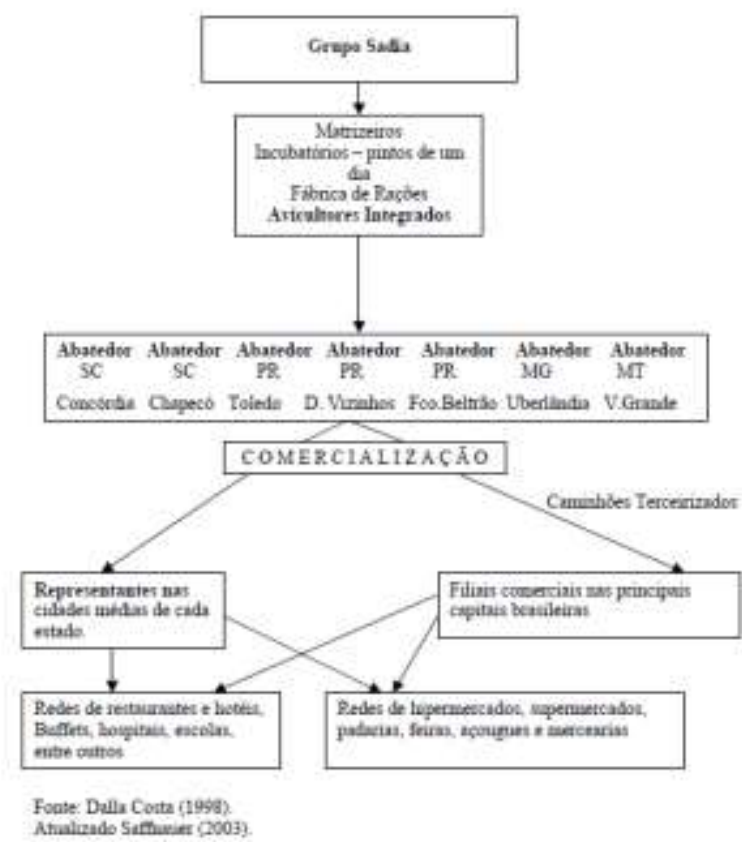

Fontes: Sadia - Dalla Costa (1998).

Na Figura 2 abaixo, apresenta o desenvolvimento que expandiu a comercialização no mercado internacional iniciado desde 1967, pela Sadia, em 2003 onde atingiu várias partes do mundo buscando e prezando assim pela qualidade de seus produtos e as boas práticas de produção.

Figura 2 - Organograma - Atuação no mercado Internacional - Sadia.

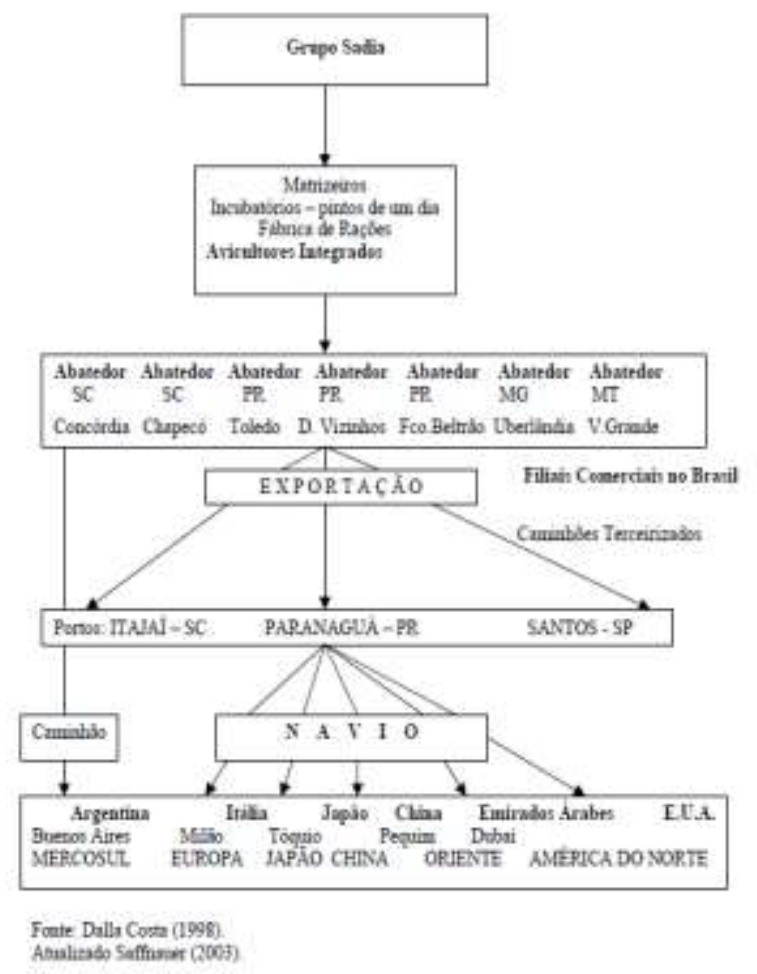

Fontes: Sadia - Dalla Costa (1998). 
Hoje, a Sadia se constitui em um conglomerado de 20 empresas, sendo a primeira empresa no ranking comercial brasileiro de aves, carnes industrializadas, suínos e bovinos, e o segundo no mercado de soja. É relevante ratificar que essas características apresentadas pela Sadia, hoje líder nacional, compõe um mix de produtos com cerca de 680 itens distribuídos para mais de 300 mil pontos de venda (Costa, 2009).

\section{Uma Nova Escalada de Investimentos na Década de 90}

Apesar que na década de 1990, os investimentos renderam a Sadia oscilações no faturamento das exportações e importações, de acordo com o histórico de produção e investimento na empresa, a partir desta década iniciou-se uma ascensão nos negócios da empresa na ordem de US\$ 567 milhões com variações. O foco principal agora era atuar no mercado internacional, sem abandonar a sua liderança nacional. Abaixo, na Figura 3, temos um breve histórico da evolução dos investimentos e produção da empresa (Costa, 2009):

Figura 3 - Volume e valor das exportações - 1973 a 2008.

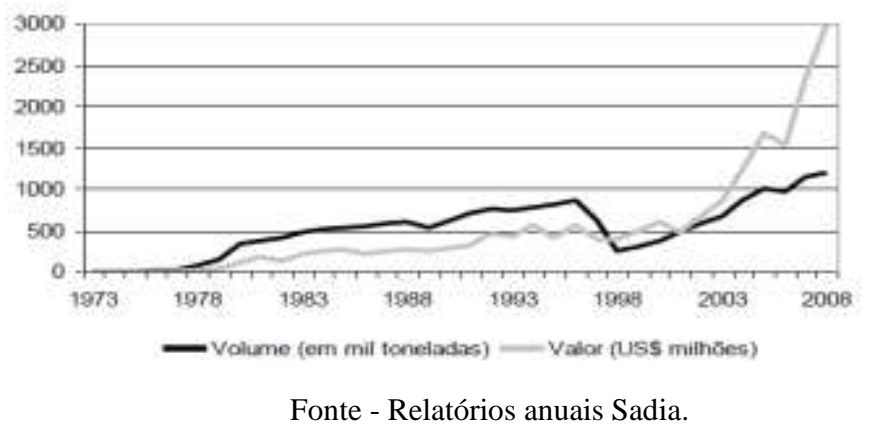

\subsection{Investimentos em unidades internacionais}

Um dos objetivos, principais, estipulados pela empresa, no comercio internacional, a partir da década de 90 e 2000 foi o de estabelecer, unidades nos principais, centros comerciais mundiais, que abrangesse o mercado de carnes suínas, aves e bovinas, com o intuito de assim consolidar sua liderança no setor frigorífico. Uma logística de importação e exportação associada aos principais países consumidores foi fundamental. Segundo relatórios Sadia_(Sadia, Relatório Anual, 1995, p. 18), “Em 1995, a Sadia consolidou sua presença nos mercados externos a partir das subsidiárias instaladas nos Emirados Árabes, Japão, Itália, Estados Unidos, Argentina e China. As atividades externas mantiveram-se estáveis em relação aos 43 países compradores". Abaixo a logomarca da unidade nos EUA da Sadia.

Figura 4 - Logomarca da Sadia nos EUA.

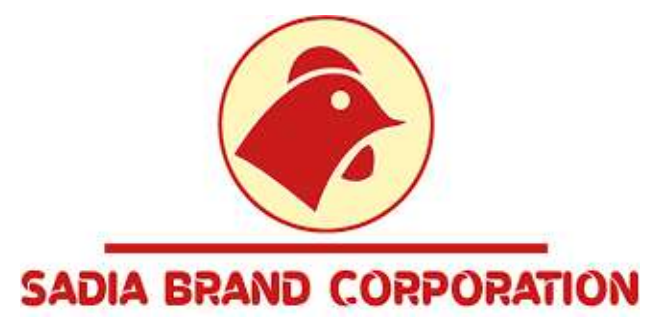

Fonte - Brazil Foodbrand Association (2021).

A instalação de escritórios nos Estados Unidos e Rússia foram importantes dado que consolidou as novas instalações físicas da Sadia que ordenaram investimentos na ordem de 90 milhões na Rússia juntamente com associada Miratorg. 
Importantes feitos também ocorreram na Holanda na ordem de US\$ 4 milhões e Emirados Árabes na ordem de US\$ 100 milhões (Costa, 2009).

Os investimentos bancados, pela empresa buscam a consolidação, no mercado internacional, não apenas pelo faturamento, mas pela especialização nos vários mercados de acordo com suas especificidades que os qualifica como rigorosos elevando o patamar de produção e diversidade nos produtos, utilizando de boas práticas de higiene e produção.

\section{Fusão da Sadia e Perdigão}

Um importante fato ocorrido, na Sadia, em sua trajetória empresarial foi a fusão ocorrida com a Perdigão, pois deste momento em diante definiu outros caminhos para as duas empresas no que diz respeito ao mercado nacional, internacional e o desenvolvimento das mesmas nesta união (Portal G1, 2009).

Em 2009, foi anunciada oficialmente a criação, do maior conglomerado brasileiro no ramo de alimentos e assim mudouse a razão social para Brasil Foods S.A. - BRF. (Sadia, 2009).

Essa fusão, garantiu que as duas companhias compartilharem a liderança em vários segmentos de produtos, constituindo a capacidade de impor preços, levando a grandes projetos de inovação e Market-share. Abaixo na Figura 5 apresenta-se a diversidade de produtos que a Brasil Foods - BRF comercializa:

Figura 5 - Diversidades de produtos da Brasil Foods S.A.

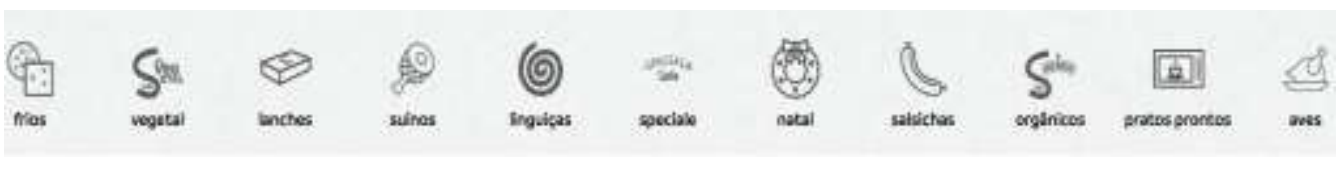

Fonte: Portal Brasil Foods S.A (2021).

\subsection{Panoramas das duas empresas: Sadia e Perdigão antes da fusão}

A primeira é a Perdigão, que é sediada em São Paulo (SP), ocupa o terceiro lugar no ranking mundial de abate de aves e está entre as dez maiores em abate de suínos, além de ser uma das principais empresas brasileiras na captação de leite e produção de processados lácteos, massas e pizzas (Perdigão, 2009). A segunda é a Sadia, onde produz e distribui alimentos derivados de carnes suína, bovina, de frango e de peru, além de massas, margarinas e sobremesas, sendo líder brasileira em alimentos industrializados e a sexta maior exportadora do país em 2008. Detém marcas como Qualy, Deline, Excelsior, Rezende e Miss Daisy (Sadia, 2009).

\subsection{Benefícios da fusão empresarial: Sadia X Perdigão}

Apesar das empresas terem um histórico empresarial de sucesso, a superação de obstáculos do mercado foi o elemento motivador, juntas conseguiram romper fronteiras tecnológicas e operacionais. Nos últimos, 10 anos Sadia e Perdigão ensaiaram três tentativas de associação nos anos de 1999, 2002 e 2006, porém só em 2008 após cinco meses de negociação foi efetivado a fusão, onde esses cinco meses de negociações envolveram mais de 60 reuniões e 30 pessoas entre investidores, advogados, banqueiros e representantes de ambos os lados (Folha on line, 2009). A tentativa de compra da Perdigão por parte da concorrente pode ser atribuída à capacidade de alavancagem financeira da Sadia.

Após a fusão das empresas, constituindo assim a Brasil Foods, posiciona-se entre as 10 empresas maiores do mundo no ramo alimentício com um faturamento de US\$ 9,47 bilhões como demonstrado na tabela abaixo: 
Tabela 1 - Ranking das 10 maiores empresas alimentícias do mundo e faturamento (2009).

\begin{tabular}{l|r|r}
\hline \multicolumn{1}{c|}{ Empreas } & $\begin{array}{c}\text { Faturamento (bilhöes de } \\
\text { USs - 12 meses) }\end{array}$ & \multicolumn{1}{c}{ Pais } \\
\hline $1^{2}$ ADM & 78,32 & EUA \\
$2^{\circ}$ Kraft Foods & 42,2 & BUA \\
$3^{\circ}$ Tyson Foodt & 27,18 & BUA \\
$4^{\circ}$ General Mallt & 14,38 & EUA \\
$5^{\circ}$ Sara Lee & 13,43 & EUA \\
$6^{\circ}$ JBS & 12,98 & Brasil \\
$7^{\circ}$ Kellogg & 12,82 & EUA \\
$8^{\circ}$ Dean Foods & 12,45 & EUA \\
$9^{\circ}$ Heinz & 10,49 & BUA \\
$10^{\circ}$ Branil Foods & 9,47 & Brasil \\
\hline
\end{tabular}

Fonte - Portal Exame.

\subsection{Estratégia empresarial}

As estratégias empresariais da fusão da Sadia e da Perdigão são resultados de vários motivos negócios, pelos quais uma estratégia de negócios é importante para as organizações, incluindo um mix de produtos funcionais e tradicionais. O carro-chefe foi incluir produtos do tipo self-cooked, baseado numa filosofia alimentar nutricional moderna incluindo baixa caloria e rapidez de cozimento.

Algumas áreas foram expandidas:

- Planejamento: Novas estratégias de negócios identificando as principais etapas a serem executadas para atingir mercados do Brasil;

- Pontos fortes e fracos: Criação de estratégias de negócios que permitiram a identificação e avaliação de os pontos fortes e fracos onde a Sadia e Perdigão de sua empresa para que você possa criar uma estratégia que otimize seus pontos fortes e compense ou elimine seus pontos fracos.

- Eficiência: A Sadia identificou estratégias de negócios que permitiu alocação de recursos de forma eficaz para suas atividades de negócios, o que automaticamente tornou mais eficiente. Ele também ajuda você a planejar com antecedência os prazos, alocar funções de trabalho e manter o controle das metas do projeto.

- Controle: Criou-se uma estratégia de negócios que controlou dois tipos de facilmente que as atividades o estão aproximando de seus objetivos.

- Vantagem competitiva: ao identificar um plano claro de como você alcançará seus objetivos, você pode se concentrar em capitalizar seus pontos fortes, usando-os como uma vantagem competitiva que torna sua empresa única no mercado.

Logo abaixo temos produtos da Brasil Foods S.A. com as novas estratégias da fusão empresarial.

Figura 6 - Produtos funcionais das novas estratégias BRF - Novo catálogo.

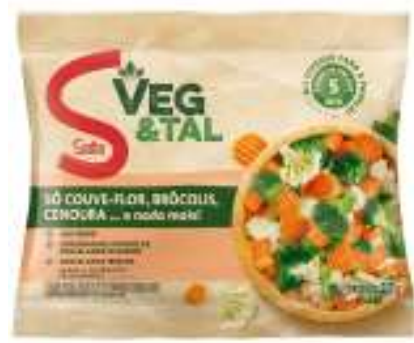

Fonte - BRF - 2021 - Novo catálogo. 


\section{Resultados}

Após a análise da história empresarial da Sadia, até sua fusão com a Perdigão, verificou-se que o mercado ao qual está inserido é um dos mais concorridos e de grandes investimentos por parte do investidor, já que o setor de carnes bovinas, suínas e aves exigem grandes aportes financeiros para poder competir em um setor de grandes empresas que abarcam várias redes alimentícias, inclusive para exportações extra continentais.

Durante a trajetória do crescimento da Sadia verificou-se que as diversificações de seus produtos foram de fundamental importância no que diz respeito a atuação em vários mercados alimentícios de carne bovina, suína e aves. Os investimentos da Sadia bastante vultuosos na casa de bilhões de reais na região sul do país em unidades filiais com o intuito de abranger o crescimento e a logística de distribuição, como também de domínio da marca evidenciaram o perfil desafiador da empresa como também a busca pela qualidade e produtividade, utilizando assim do Market Share como foco de seus objetivos.

Observou que a expansão no mercado internacional levou o patamar da empresa ao alto nível no setor frigorífico nacional, competindo assim com grandes empresas internacionais. Na fusão com a Perdigão formando então a BRF, uma ação também estratégica consolidou a capacidade empresarial das empresas, apesar de que houve críticas referentes ao monopólio comercial do setor no país e extensa negociação por parte dos diretores das mesmas.

\section{Considerações Finais}

O perfil inovador e investidor da Sadia foi de fundamental importância para o seu desenvolvimento, em um mercado frigorífico, que exige investimentos altos, decisões empresariais certas e uma economia nacional propícia a esse crescimento. Pode-se concluir que o mercado internacional necessita de empresas que corram em busca da qualidade dos produtos, da diversidade e no setor alimentício das boas práticas de produção e higiene, sem que com essa união não perca o foco da logística e lucratividade das ações. Desta forma, a Sadia conseguiu conquistar com trabalho sério através de seu início com o comerciante Attílio Fontana dando os primeiros passos.

A criação da BRF, em 2008, representa a criação de uma multinacional brasileira que não só é uma das maiores exportadoras do país, mas foi um importante passo para desenvolver, mais ainda e poder agregar mais empresas demonstrando sua capacidade de crescimento no mundo. O Brasil ganha uma importante empresa que contribui para economia mundial, um atrativo no mercado de capitais.

Para trabalhos futuros, com relação ao processo de fusão entre a Sadia e Perdigão, um estudo direcionado aos resultados produtivos, comerciais e financeiros seria de extrema importância, pois fusões empresariais deste tipo impactam não só na concorrência, mas também na economia de grande parte da região, onde se localizam os centros produtivos. Outro importante foco de estudo, envolvendo fusão, é apresentar até onde no comercio internacional, recebe o impacto dessa união com relação a qualidade dos produtos, produtividade e preço, pois a Brasil Foods (Sadia) se tornou a décima Transnacional no mundo.

\section{Referências}

A história da Sadia (2021) https://www.sadia.com.br/sadia.

Batista, L.L., Duarte, J. \& Barros, A. (Orgs). (2006). Métodos e técnicas de pesquisa. São Paulo. Atlas. 384 p. $2^{\circ}$ Ed. São Paulo.

BRF Global. (2021) "Nossa história”. https://www.brf-global.com/sobre/a-brf/nossa-historia/.

BRF Brasil Foods. (2021) http://www.brasilfoods.com/paginas.cfm?area=0\&sub=1.

Costa, D. (2009) Brasil Foods: a fusão entre Perdigão e Sadia. Revista Economia \& Tecnologia. https://revistas.ufpr.br/ret/article/view/27274/18177.

Costa, A. D. (2009). “A Sadia e sua experiência no mercado internacional”. Revista Economia \& Tecnologia. 5(2). https://doi.org/10.5380/ret.v5i1.27321. 
Costa, A. D. \& SANTOS, E. R. S. (2009). “Brasil Foods: a fusão entre Perdigão e Sadia”. Revista Economia \& Tecnologia, 5 (2).

Dalla, C. A., Petit, P. \& Bittencourt, M. (2009). Innovations, technologies and economic development: An evolutionary view of the Brazilian poultry industry and its firms. III Research Workshop on Institutions and Organizations. São Paulo: USP, IBMEC and FGV-SP.

Dalla, C. A. (1998). Agroindústrias brasileiras e sua estratégia de ocupação do território Nacional. Rio Claro. 23 (3), $39-64$.

Folha Online (2009). A Perdigão e a Sadia fizeram pelo menos cinco tentativas de fusão. http://www1.folha.uol.com.br/folha/dinheiro/ult91u567495.html.

Fontgalland, I. (2021) MEC - slides, UFCG.

Portal G1. (2009). Economia e Negócios - NOTÍCIAS - União de Sadia e Perdigão cria 'gigante' brasileira dos alimentos". http://g1.globo.com/Noticias/Economia_Negocios/0,,MRP1125247-9356,00.html.

Portal G1. (2009). Economia e Negócios - NOTÍCIAS. Perdigão e Sadia anunciam 'grande multinacional' do setor de alimentos. http://g1.globo.com/Noticias/Economia_Negocios/0,MUL1159465-9356,00-ERDIGAO+E+SADIA+ANUNCIAM+CRIACAO+DA+BRASIL+FOODS.html.

Portal G1. (2009). Conheça os passos do CADE para aprovar ou rejeitar a fusão Sadia-Perdigão. http://g1.globo.com/Noticias/Economia_Negocios/0,MUL1161471-9356,00-CONHECA+OS+PASSOS+DO+CADE+PARA+ APROVAR+OU+ REJEITAR $+\mathrm{A}+\mathrm{FUSAO+SADIAPERDIGAO} \cdot \mathrm{html}$

Portal Exame. (2009). "Fusão Sadia-Perdigão será julgada no Cade na quarta”. https://exame.com/negocios/fusao-sadia-perdigao-sera-julgada-no-cade-naquarta/.

Portal UOL. (2009). "Perdigão e Sadia fizeram pelo menos cinco tentativas de fusão". https://www1.folha.uol.com.br/mercado/2009/05/567495-perdigao-esadia-fizeram-pelo-menos-cinco-tentativas-de-fusao.shtml.

Sato, G. S.(1998). “Estratégia e estrutura organizacional: O caso Sadia”. São Paulo. [s.d.], p. 16.

Sadia S. A. e Perdigão S. A. (2021) Análise da trajetória histórica e do desempenho que antecederam o seu processo de fusão. Taffarel. Revista Eletrônica de Ciência Administrativa. 2009.

Sadia, Relatórios Anuais. 1976 a 2007.

Wimmer, R. D. \& Dominick, J. R. (1996). La investigación científica de los medios de comunicación: uma introdución a sus métodos. Barcelona: Bosch, 1996.

Yin, R.K. (2015). O estudo de caso. Porto Alegre: Bookman. 